\title{
Automatic Voltage Regulator (AVR) Optimization Based on PID Using the Hybrid Grey Wolf Optimization - Genetic Algorithm (HGWGA) Method
}

\author{
Anas Setiawan \\ Electrical Engineering \\ Department \\ Brawijaya University \\ Malang, Indonesia
}

\author{
Panca Mudjirahardjo \\ Electrical Engineering \\ Department \\ Brawijaya University \\ Malang, Indonesia
}

\author{
Wijono \\ Electrical Engineering \\ Department \\ Brawijaya University \\ Malang, Indonesia
}

\begin{abstract}
In the generator set (genset), the voltage stability system is affected by the excitation system controlled by control circuit called AVR (Automatic Voltage Regulator). One of the important components in the AVR system is the algorithm of the controller. The application of the PID control method has been widely used in the design of AVR controllers. This study applies the GWO-GA (Grey Wolf Optimization - Genetic Algorithm) hybrid method on PID parameters setting. The best transient automatic voltage regulator (AVR) response results were obtained when using the hybrid genetic algorithm - grey wolf optimization (HGAGW) method with a fitness score of 4.3039 , the Grey wolf optimization (GWO) method with a fitness score of 4.5059, and the genetic algorithm (GA) method with a fitness score of 6.0214 .
\end{abstract}

Keywords: Generator set, AVR, PID, hybrid GWO-GA

\section{PRELIMINARY}

Consumption of electrical energy has become a primary need for all lines of community life. Starting from households to industry, it is highly dependent on the availability of electrical energy in the industrial world, the use of electrical energy can increase productivity and efficiency in the production system. The electricity consumption increase in Indonesia is influenced by increasing population and economic growth [1].

Indonesia is one of the electricity deficit countries. It can be seen from the data published by PLN, which states that the level of electrification in Indonesia is $88.3 \%$ in 2015 [2]. So that at the end of 2015, PLN made a construction program for electricity generation of $35,000 \mathrm{MW}$ with an electrification target of $97.4 \%$ in 2019. Electrification in Indonesia still could not run optimally, one of the causes is Indonesia's geographical location consisting of islands. Due to the level of availability of electrical energy in Indonesia which is still deficit to the level of its needs, the use of generator set (genset) is still used as an alternative as a reserve of electrical energy sources for many consumers.

In the generator set (genset), the voltage stability system is influenced by the excitation system controlled by a control circuit called the AVR (automatic voltage regulator). One of the important components in the AVR system is an algorithm of the controller. The algorithm of a controller has a closed loop-based control method. The controller algorithm functions to process the signal from the sensor then processed into an output score to regulate the excitation flow on the exciter. The use of the control method in the AVR system has the purpose of dealing with the problem of voltage stability at nonlinear load and can also optimize the score of time responses [3].
The control of Proportional Integral Derivative (PID) method has been widely implemented in industrial systems such as chemical processes, biomedical processes, thermal processes, and many others. The advantages of the PID control method are to use and has relatively stable performance (Busra, 2019). Based on this, the use of the PID control method has been widely used in the design of the AVR controller. The optimization of PID control methods is carried out through the tuning parameters of KP, KI, and KD. The PID parameter assistance method carried out conventionally using the Ziegler-Nichols method does not provide optimum performance on the plan [4]. Many studies have been conducted to find optimum tuning methods using Artificial Intelligence (AI).

Several studies have been conducted in determining PID parameters, including using the Artificial Intelligent (AI) method. One of the studies that have been done is the use of the Grey Wolf Optimization (GWO) method based on the controller on the AVR system (Automatic Voltage Regulator) [4]. Based on studies conducted using the GWO method obtained transient response which had an overshoot of $1,1301 \mathrm{~V}$ and settling time of $0.7739 \mathrm{~S}$. In other studies entitled The AVR system controller design using the PIDbased Grey Wolf Optimization (GWO) method was obtained by the results of the Transient Step Response with an overshoot score of $1.1301 \mathrm{~V}$ and settling time of $0.7739 \mathrm{~S}$ [5].

Based on the discussion above, researchers will use the GWO-GA hybrid method (Grey Wolf Optimization Genetic Algorithm) in PID parameters settings in the hope of improving the transient response from the system. 


\section{THEORETICAL BASIS}

Automatic Voltage Regulator (AVR) generally consists of four main components, namely amplifiers, exciter, synchronous generators, and sensors. In every generator set (genset) there is an AVR as one of the components of the compulsion. The main objective of the Automatic Voltage Regulator (AVR) in the generator set (generator) system is as a manipulator so that the output voltage on the Synchronous generator terminal is maintained and stable at a certain score.

The PID control method is widely used in the AVR control system because it has a simple structure and has a stable performance of disturbances [6].

\subsection{PID Controller on the AVR system}

The stability of power parameters (voltage and frequency) in synchronous generators is a very important thing. Where it depends on the performance of the Automatic Voltage Regulator (AVR) which functions to regulate the voltage of the synchronous generator to be maintained. Until now, the PID controller is still widely used in the Automatic Voltage Regulator (AVR) system due to it is easy to use and cheap [7].

PID Controller (Proportional, Integral, Derivative) is a controller that able to improve the level of accuracy of a plant system that has the characteristics of feedback on the system. PID controller calculates and minimizes the error or difference score between the process output of the input or set point given to the system.

\section{A.Proportional Controller}

Proportional / gain controllers act as amplifiers that able to change the output of the system proportionally without providing a dynamic effect on the controlling performance. There are two types of proportional controllers, namely analog and digital. The equation from analog and digital proportional controllers is stated in the equation:

$P_{\text {out }}=K_{e} \cdot E(t)$

$P_{\text {out }}=K_{e} \cdot E_{N}$

Where:

$P_{\text {out }}=$ Output of the proportional controller

$K_{n} \quad=$ Constants Gain

$$
\begin{aligned}
& E(t)=\text { Error recognized in continuous time } \\
& E_{N}=\text { Error recognized in discrete }
\end{aligned}
$$

Settings with using proportional controllers able to improve the transient response from the system, especially rise time. This controller is also able to fix settle time from the system.

\section{B.Integral Controller}

Integral controller is a controller that serves to improve a product response from the system so that this controller able to minimize the error system. There are two types of integral controller, namely analog and digital. The equation from analog and digital integral controllers is stated in the equation:

$$
\begin{aligned}
& I_{\text {out }}=K_{\mathrm{i}} \int_{0}^{t} E(\tau) d \tau . \\
& I_{\text {out }}=\frac{K_{\mathrm{c}} \Delta t}{T_{i}} \sum_{\mathrm{i}=1}^{N} E_{\mathrm{i}} .
\end{aligned}
$$

Where:

$$
\begin{aligned}
& I_{\text {out }}=\text { Output of the integral controller } \\
& K_{i} \quad=\text { Constants Integral } \\
& E(\tau)=\text { Error recognized in continuous time } \\
& \tau \quad=\text { Variable of integration } \\
& T_{i} \quad=\text { Integral time } \\
& \Delta t \quad=\text { Sampling Period } \\
& E \quad=\text { Error recognized in discrete }
\end{aligned}
$$

\section{Derivative Controller}

Derivative controllers are controllers that mainly function to correct the transient response from the system. There are two types of derivative controllers, namely analog and digital. The derivative controller equation can be stated in the following equation:

$D_{\text {out }}=K_{d} \cdot \frac{d}{d t} E(t) \ldots \ldots \ldots \ldots$
$D_{\text {out }}=\frac{K_{c} T_{d}}{\Delta t}\left(E_{N}-E_{N-1}\right)$.

Where:

$D_{\text {out }}=$ Output of the derivative controller

$K_{d} \quad=$ Constants Derivative

$E(t)=$ Error recognized in continuous time

$P_{\text {out }}=$ Output of the derivative controller

$T_{d} \quad=$ derivative time

$\Delta t \quad=$ Sompling time

$E_{N}, E_{N-1}=$ Error recognized in discrete

\subsection{Genetic Algorithm}

The genetic algorithm provides the option to determine the score of parameters by duplicating genetic reproduction methods, new chromosome formation, gene migration processes, and natural selection as happens in living organisms. Generally, genetic algorithms can be illustrated through the diagram in Figure 1 


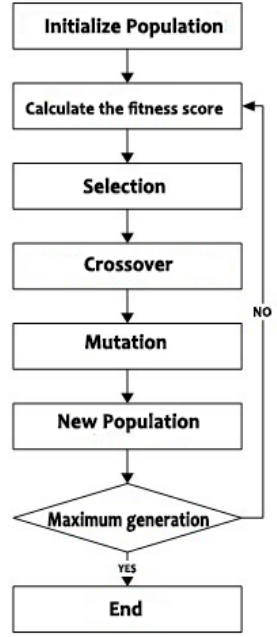

Figure 1. General Structure Diagram Of Genetic Algorithms

\subsection{Grey Wolf Optimizer (GWO)}

The Grey Wolf Optimizer algorithm is an algorithm inspired by the behavior of wolf hunting in nature. Grey wolf is considered a peak predator, which means that the grey wolf is at the top of the food chain. Grey wolf also has a high socially dominant hierarchy. The leaders who are the first level will be referred to as alpha, the second level is beta, third level is delta, while the last level is omega. In addition to the social hierarchy of wolves, hunting in groups is another interesting behavior of grey wolves.

The social hierarchy of the grey wolf method is categorized based on the fitness score. The distribution of social hierarchies from grey wolves is divided into four as shown in Figure 2.

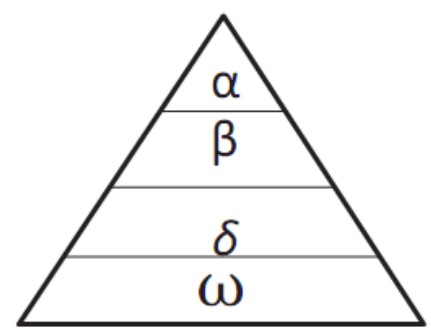

Figure 2. Social Hierarchy of Grey Wolf

\section{METHOD}

\subsection{Automatic Voltage Regulator (AVR) Modeling System}

An automatic voltage regulator (AVR) system is formed by four main components, namely amplifier, exciter, generator, and sensor. Each of the components has the transfer function shown in Figure 3.

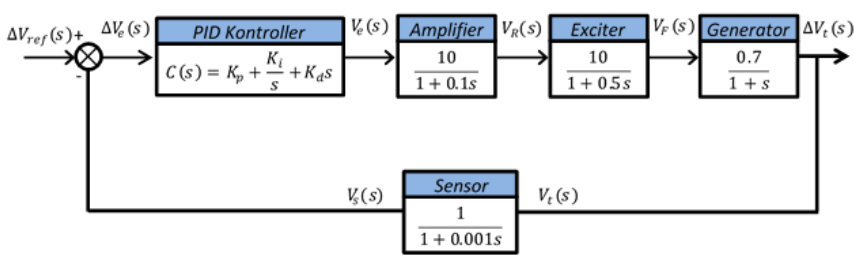

Figure 3. AVR system diagram block with PID controller

\subsection{PID Controller Design}

In this study, researchers used a PID controller as a control method that functions to improve the quality of the Automatic Voltage Regulator (AVR) response in maintaining the stability of the generator output voltage. The parameters of the PID control method in the form of KP, KI, and $\mathrm{KD}$ scores are determined using the Genetic Algorithm (GA) algorithm, Grey Wolf Optimization (GWO) and Hybrid Grey Wolf Optimization - Genetic Algorithm (GWO-GA). The PID-based Automatic Voltage Regulator (AVR) system diagram block with an Installation of the Artificial Intelligent (AI) method is shown in Figure 4.

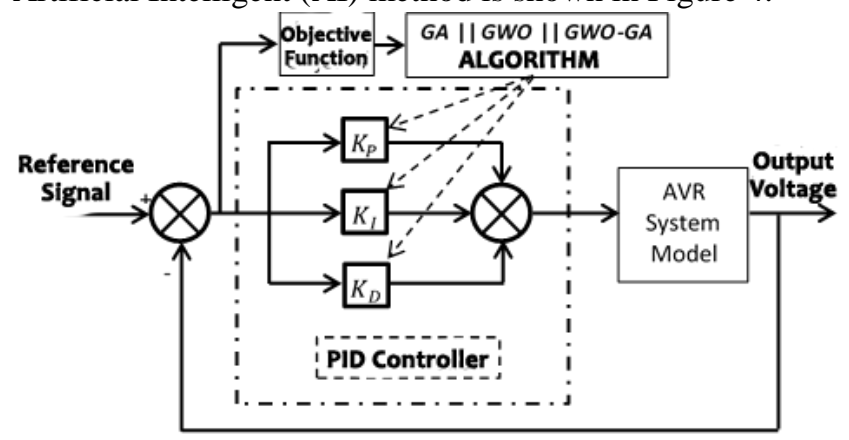

Figure 4. PID-based AVR system diagram block using the installation of Artificial Intelligent (AI) method

\subsection{Objective Function Design}

The objective function has a very important role in the Artificial Intelligent (AI) method. The objective function works to evaluate the performance of a solution generated from the Artificial Intelligent (AI) method.

In this study, researchers used ITAE - Modified as the objective function. The objective function of ITAE Modified is the development of the objective function of ITAE (Integral of Time Multiplied by Absolute Error). The equation of the objective function of ITAE and ITAE Modified is shown in the equation below:

$$
\begin{aligned}
& \text { ITAE }=\int_{0}^{\tau} t|e(t)| d t \\
& I T A E-\text { Modified }=\left.\int_{0}^{\tau} t\right|_{e}(t) \mid d t+w_{1}, o_{V}+w_{2} \cdot e_{S S} \\
& +w_{2} \cdot t_{s}+w_{4} \cdot t_{y}
\end{aligned}
$$




\section{Where:}

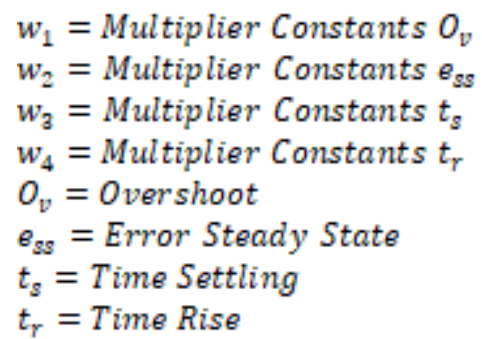

In the objective function of ITAE - Modified there is a modification of variables addition from the original function of ITAE. The addition of parameter variables used includes overshoot, state steady error, time settling, and time rise. In the ITAE - modified using the equation of $w_{1}, w_{2}, w_{3}$ and $w_{4}$. Determination of the multiplier constant score based on the priority level of the variable to be optimized. In this study, the score of the multiplier factor constant is determined as:

$$
\begin{aligned}
& w_{1}=1.5 \\
& w_{2}=15 \\
& w_{3}=7 \\
& w_{4}=1
\end{aligned}
$$

Based on the determination score of the multiplier factor shown above, it is obtained an objective function as follows:

$$
\begin{aligned}
& I T A E-\text { Modified }=\int_{0}^{\pi} t\left\|_{e}(t)\right\|_{d}+1,5 x O_{D}+15 x e_{s e} \\
& +7 x t_{g}+1 x t_{r}
\end{aligned}
$$

\subsection{Genetic Algorithm (GA) Design}

One method of Artificial Intelligent (AI) was used in this study, namely Genetic Algorithm (GA) in the PID parameters settings process. The Genetic Algorithm (GA) method is a stochastic algorithm implemented from the biological evolutionary process. The Genetic Algorithm (GA) method has three main operators, namely reproduction, crossover, and mutations. The flowchart design of the Genetic Algorithm method is shown in Figure 5.

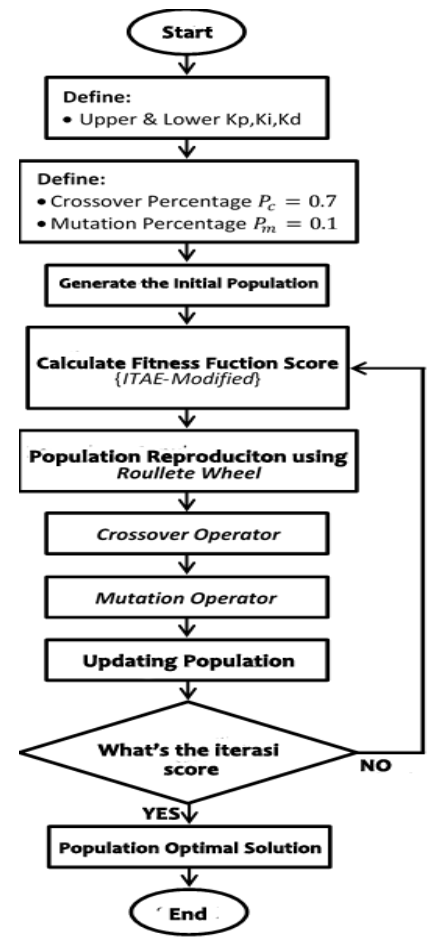

Figure 4.4 Genetic Algorithm (GA) Flow Method Diagram

\subsection{Grey Wolf Optimization Design (GWO)}

This study uses one of the Artificial Intelligent (AI) methods, namely Grey Wolf Optimization (GWO) in the process of tuning PID parameters. The method of Grey Wolf Optimization (GWO) is a swarm intelligence-based metaheuristic method based on the behavior of a group of grey wolves in hunting prey. The step in the GWO technique is based on social hierarchy, tracking, siege, and attacking prey. GWO has a group of hunting (optimization) with three settlements namely Alpha, Beta, and Delta with Alpha settlement is the best solution. The flowchart of the design of the Grey Wolf Optimization (GWO) method is shown in Figure 6. 


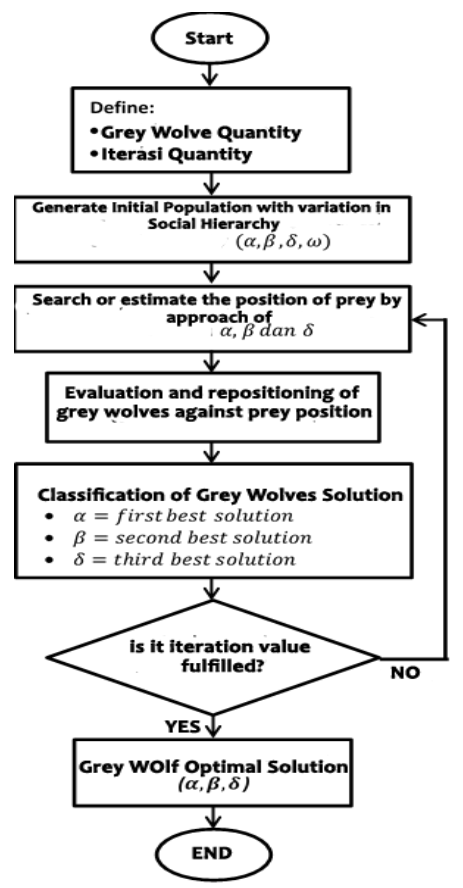

Figure 6. Grey Wolf Optimization (GWO) Flow Method Diagram

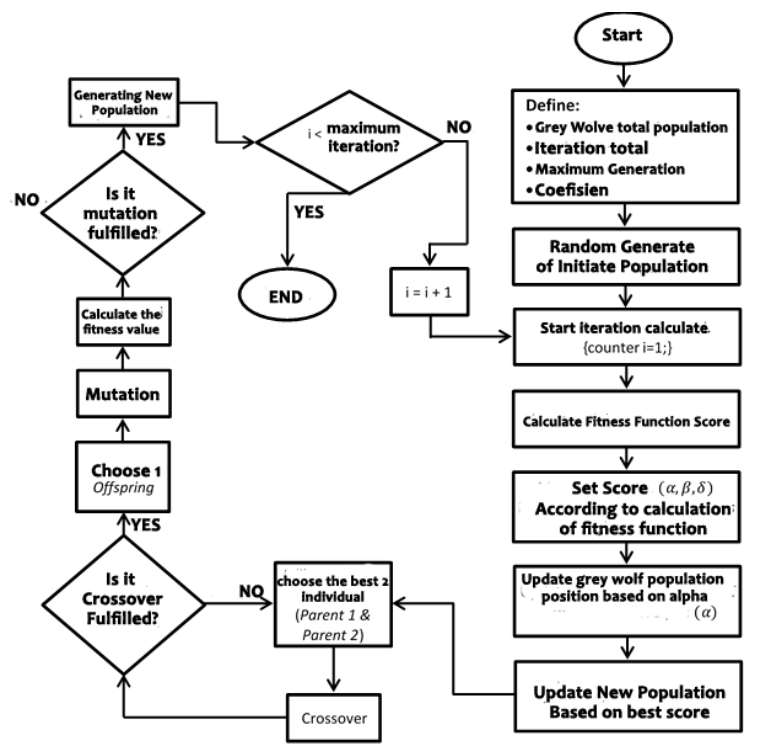

Figure 7. Hybrid Grey Wolfs Optimization - Genetic Algorithm (HGWGA) Flow Method Diagram

\subsection{Grey Wolf - Genetic Algorithm (HGWGA) Design}

The HGWGA method combines the GWO and GA methods. The hybrid process of both methods is carried out serially. In this case, the first process is done by using the Grey Wolf Optimization (GWO) method first, then continued using the Genetic Algorithm (GA) method. The flowchart method of hybrid grey wolf optimization - genetic algorithm (HGWGA) is shown in Figure 7.

Table 1. Test result summary of GA, GWO dan GA-GWO on PID Based Automatic Voltage Regulator (AVR) system

\begin{tabular}{c|c|c|c|c|c|c|c|c|c|c}
\hline & \multicolumn{3}{|c|}{ PID Parameter } & Rise & Settling & $\begin{array}{c}\text { Maximum } \\
\text { Overshoot } \\
(\%)\end{array}$ & $\begin{array}{c}\text { Peak } \\
(\mathrm{PU})\end{array}$ & $\begin{array}{c}\text { Peak } \\
\text { Time (s) }\end{array}$ & $\begin{array}{c}\text { Fitness } \\
\text { Time (s) }\end{array}$ & $\begin{array}{c}\text { Elapsed } \\
\text { Time (s) }\end{array}$ \\
\hline $\begin{array}{c}\text { Genetic Algorithm } \\
\text { (GA) }\end{array}$ & 0.6477 & 0.4592 & 0.2476 & 0.3149 & 0.4756 & 1.5813 & 1.0158 & 0.6283 & 6.0214 & 30.7106 \\
\hline $\begin{array}{c}\text { Grey Wolf } \\
\text { Optimization } \\
\text { (GWO) }\end{array}$ & 0.6278 & 0.4316 & 0.2458 & 0.3238 & 0.4986 & 0.4516 & 1.0045 & 0.6239 & 4.5059 & 39.5309 \\
\hline Hybrid GA-GWO & 0.6030 & 0.3808 & 0.2242 & 0.3497 & 0.5447 & 0.0909 & 1.0009 & 0.6884 & 4.3039 & 42.7498 \\
\hline
\end{tabular}

\section{RESULT AND DISCUSSION}

Based on the results of the Automatic Voltage Regulator (AVR) test-based controller by using the Genetic Algorithm method, Grey Wolf Optimization and Hybrid Genetic Algorithm - Grey Wolf Optimization that has been carried out has different characteristics. The summary of the test results of the three methods is shown in Table 1.

Based on the test results of the three methods shown in Table 1 can be seen that the best fitness score is obtained when using the Hybrid Genetic Algorithm - Grey Wolf Optimization method with a score of 4,3039 . It can be concluded that by using the Hybrid GA-GWO method obtained the best transient response compared to the GA and GWO method. This refers to the lowest fitness score achieved by each method. The disadvantage of the GAGWO hybrid method is to have a higher execution time (Elapsed Time) compared to the GA and GWO methods. It is because there are additional crossover and mutation functions in the process of Hybrid GA-GWO that result in additional execution time. 


\subsection{Automatic Voltage Regulator (AVR) Loading Test}

The automatic voltage regulator (AVR) loading test is needed to determine the transient response of the system to reach the set point score when there is a disturbance due to the effect of loading. In addition, it is also to determine the comparison of the control response to the Artificial Intelligent (AI) method implemented in the AVR control system. The automatic voltage regulator (AVR) loading test is carried out by providing a disturbance signal to the system. The disturbance signal is given at the system output point and the controller output point. The diagram block of the automatic voltage regulator (AVR) loading test is shown in Figure 8.

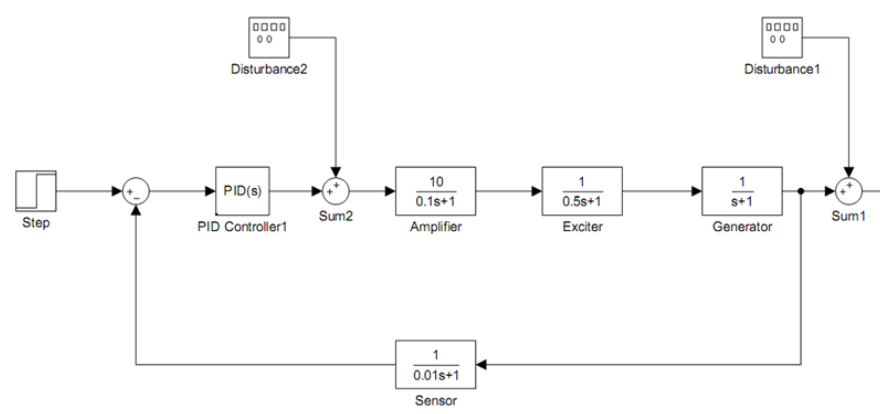

Figure 8. The diagram block of the automatic voltage regulator (AVR) loading test

The results of the load / disturbance test (disturbance 1) are carried out by providing a disturbance signal at the output position of the AVR system (Sum1). The score of the interference signal in this test is $0.25 \mathrm{PU}$. The test results for disturbance are shown in Figure 9.

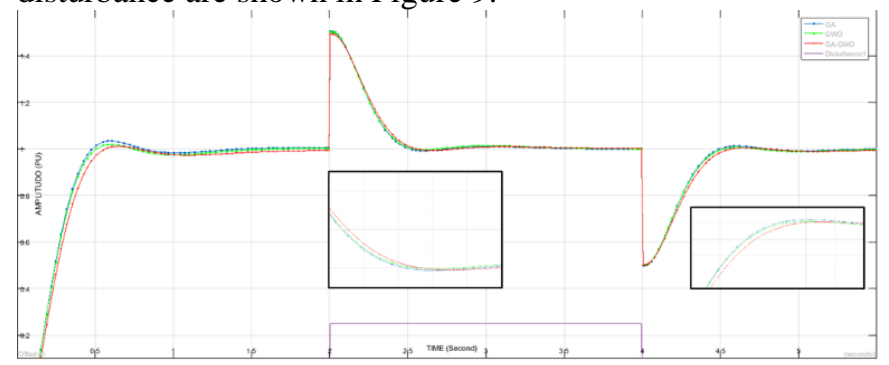

Figure 9. Results Test of Disturbance 1 with a Score of 0.25 PU

The test result for disturbance 2 is carried out with providing a disturbance signal at the output position of the PID controller (Sum2). The score of the interference signal in this test is $0.25 \mathrm{PU}$. The test results for disturbance are shown in Figure 10.

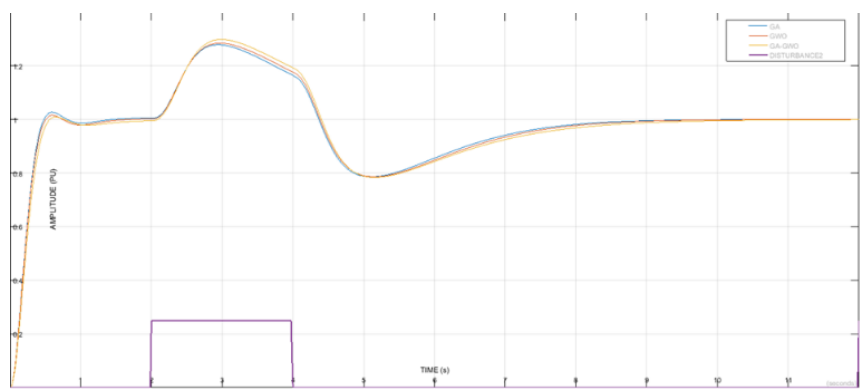

Figure 10. Results Test of Disturbance 2 with a Score of 0.25 PU

\section{CONCLUSION}

Based on the results and discussion of automatic voltage regulator (AVR) optimization based on PID controllers using the Hybrid Genetic Algorithm - Grey Wolf Optimization method, the best automatic voltage regulator (AVR) transient response is obtained when using the hybrid genetic algorithm - grey wolf optimization (HGAGW) method with fitness score of 4.3039. The second is grey wolf optimization (GWO) with a fitness score of 4.5059. The third is a genetic algorithm (GA) with a fitness score of 6.0214.

\section{REFERENCES}

[1] Bahran ,Teuku B. 2017. Konsumsi Energi Listrik, Pertumbuhan Ekonomi dan penduduk terhadap Emisi Gas Rumah Kaca Pembangkit Listrik di Indonesia. Skripsi. Universitas Syiah Kuala.

[2] PT. PLN (Persero). 2015. 35000MW Untuk Indonesia Laporan Tahunan 2015, (Online), (http://www.pln.co.id, diakses 23 Januari 2021)

[3] Ahmed M. Mosaad, Mahmoud A.A., Almoataz Y.A. 2019. Whale optimization algorithm to tune PID and PIDA controllers on AVR system. Ain ShamsEngineering Journal 10 (2019) 755-767.

[4] Ziegler J. G. and N. B. Nichols. 1942. Optimum settings for automatic controllers. Trans. ASME, vol/issue: 64(8), pp.759/768-759/768.

[5] Rvindra Kumar K. 2019. Grey Wolf Optimization Algorithm based PID controller design for AVR Power system. 2nd International Conference on Power Energy, Environment and Intelligent Control (PEEIC).

[6] Busra O. 2019. Optimally Tuned PID Controller Design for an AVR System : A Comparison Study. Internationa Journal of Multidisciplinary Studies and Innovative Technologies 3 (2019) 157161.

[7] Ching-Chang W. 2009. Optimal PID controller design for AVR system". Tamkang Journal of Science and Engineering,Vol.12,No.3,pp.259270. 